THE NATIONAL HEALTH SERVICE

Edited by Max Sorsby, L.M.S.S.A. Pp. xii +267 . Edinburgh: E. \& S. Livingstone Ltd. 1953. I2s. $6 \mathrm{~d}$.

The introduction of the National Health Service into British medicine was a major upheaval and now that it has been in action long enough for things to quieten down it is fit and proper for a small manual, such as this, to be published. On quietly browsing through it one can "get the measure " of the service as it is today.

This book is short and readable, and it can be highly recommended to all doctors employed in the Health Service. It is produced by a general practitioner, and we believe that all such should read it as it makes clear the reasons for some of the more obscure rules and regulations of the service. It is packed, too, with information that will contribute to the well-running of a medical practice.

\section{PARKINSON'S DISEASE AND ITS SURGICAL TREATMENT}

By L. C. Oliver, F.R.C.S. Pp. viii +88 , with 12 illustrations. London: H. K. Lewis \& Co. Ltd. 1953. I 2 s. 6d.

This book is a monograph which contains in detail the case reports of all the Parkinsonian patients whom Mr. Oliver has treated surgically.

We cannot but admire his stalwart approach to this subject, and the hard work that he has put into the care of his patients clearly deserves great praise. From his results it is seen that his efforts have been far from wasted. He has studied $\mathrm{I}, 000$ cases, 300 of them in a detailed form in hospital, and of the latter 93 have been operated upon. Mr. Oliver is bold in his surgery, yet his extensive section of the lateral column has not been followed by the side effects one might imagine.

This book contains an original contribution to the treatment of Parkinsonism. Whilst it is felt that such a work would have been better confined to a scientific paper rather than brought out in book form, we wish this to be only a minor criticism.

\section{A TEXTBOOK OF MEDICAL TREATMENT}

Edited by D. M. Dunlop, B.A., M.D., F.R.C.P., L. S. P. Davidson, B.A., M.D., F.R.C.P., and SiR JOHN MCNEE, D.S.O., M.D., D.Sc., F.R.C.P., F.R.F.P.S. Sixth edition. Pp. xvi + I,023, with 44 illustrations. Edinburgh: E. \& S. Livingstone Ltd. I953. 50 S.

This textbook was first published just before the war, and this is the fourth edition to appear in nine years. The way in which it has been kept up to date is commendable, and is partly responsible for its widespread popularity. A completely new index has been made for this edition, and all doses are now in the metric system (apothecaries' has been included in brackets for the older drugs). Professor Cameron, Sir Alexander Biggam, Professor Alstead, Dr. Meiklejohn, Dr. Rennie and
Professor Rodger now contribute new chapters on tuberculosis, tropical diseases, care of old people, nutritional disorders, nephritis and psychotherapy respectively. The book is therefore remarkably complete as well as up to date, and the information is clearly laid out and readily available. Students, practitioners and general physicians will find in it clear and authoritative information. On reading through a few of the sections one notices here and there minor omissions or faults of emphasis. For instance, in the account of the antihistamine drugs, Phenindamine (Thephorin) is not mentioned, although it must be one of the most widely used, and the sentence "sleepiness is the principle reaction with all the antihistamine drugs' should be modified, for this drug has usually a mildly stimulant action. The account of the sulphonamides includes the statement: "There is no good evidence that the compounds for systemic use differ greatly ... . in their liability to produce toxic side-effects.' Few clinicians would agree with this, for renal complications after sulphamerazine are sufficiently common to make the use of this drug outside hospital unjustifiable in the opinion of many. It is not true to imply that these dangerous complications are common with sulphadimidine. Some reference to the advantages claimed for mixtures of three sulphonamides should also be made. On the other hand, the advice given with regard to the administration of penicillin is in keeping wits recent views, though in future editions it seem probable that even more emphasis will be placed on the use of crystalline penicillin. The use of ACTH and cortisone is admirably described, and it is a tribute to the authors that there should be 30 separate references to these two agents in the index. On the other hand, one or two sections lag behind, that on colitis, for instance, stating that ileostomy is nowadays the only operation to be considered, and making no reference to that of colectomy. It must be disappointing to surgeons who have done so much for this condition to read that while some patients apparently recover as a direct result of operation, almost an equal number die. After this, to include a paragraph on antidysenteric serum is odd indeed.

\section{CIBA FOUNDATION COLLOQUIA ON ENDOCRINOLOGY}

Vol. V. Bioassay of Anterior Pituitary and Adrenocortical Hormones

General Editor for the Ciba Foundation, G. E. W. Wolstenholme, O.B.E., M.A., M.B., B.Ch., assisted by M. P. CAMERoN, M.A., A.B.L.S. Pp. xiv +228 , with 53 illustrations. London: J. \& A. Churchill, Ltd. 1953. $25 \mathrm{~s}$.

In reviewing Vol. IV of this series of $\mathrm{Ciba}$ Foundation Colloquia on Endocrinology, the $\theta$ present writer remarked upon the valuable and novel contribution to scientific literature that these $\stackrel{\mathscr{D}}{\rightarrow}$ publications represented. They may be regarded 7 as a series of significant conversations between prominent experts in the chosen field, the starting 